\title{
Detection of endometrial cancer in postmenopausal women by transvaginal ultrasonography and colour flow imaging
}

\author{
Thomas H Bourne, Stuart Campbell, \\ Malcolm I Whitehead, Patrick Royston, \\ Christopher V Steer, William P Collins
}

Department of Obstetrics and Gynaecology, King's College School of Medicine and Dentistry, London SE5 8RX

Thomas H Bourne, MB, research registrar

Stuart Campbell, FRCOG, professor

Malcolm I Whitehead, FRCOG, senior lecturer research registrar

William P Collins, DSC, professor

\section{Department of Medical} Physics, Royal

Postgraduate Medical

Patrick Royston, MSC, senior lecturer

Correspondence to: Professor Collins. Christopher V Steer, MRCOG, School, London W12 0NN

BrMed f 1990;301:369

About 3700 new cases of endometrial cancer are reported in the United Kingdom each year. The incidence of the disease increases considerably during the fifth decade of life and reaches a peak between the ages of 60 and 65 . Uterine bleeding is the most common initial symptom after the menopause and necessitates invasive investigation (for example, dilatation and curettage). About a tenth of women with postmenopausal bleeding have endometrial cancer. A less invasive technique with a high rate of detection of the disease and a low rate of false positive diagnoses would be of value for selecting those women who require diagnostic surgery.

Pelvic ultrasonography yields detailed images of the uterus. Although a thick endometrium may be a sign of pathological processes, no morphological features that are unique to malignant disease have been identified.' Recently the use of transvaginal pulsed Doppler probes, with and without colour flow imaging, has shown that uterine blood flow changes during the menstrual cycle. ${ }^{2}$ Furthermore, transvaginal ultrasonography with colour flow imaging has shown that the presence of intratumoral vascularisation with a low impedance to blood flow can be used as an end point in screening programmes for early ovarian cancer. ${ }^{34}$ We report the use of these techniques to measure the impedance to uterine arterial and intratumoral blood flow and hence detect endometrial cancer in women with postmenopausal bleeding.

\section{Patients, methods, and results}

We scanned 54 women who had not menstruated spontaneously for at least one year. All underwent dilatation and curettage. Twenty controls (aged 43-63 (mean 53)) with histologically normal endometrium were recruited from the menopause clinic before starting a clinical trial of hormone replacement therapy. Thirty four patients (aged 49-83 (mean 62)) with postmenopausal bleeding who were suspected of having endometrial cancer were recruited from the gynaecological outpatient clinic. Twenty four women had already undergone dilatation and curettage seven to 10 days before scanning, and the tissues had been sent for routine histological examination. In the remainder biopsy was performed after ultrasonography. There was no histological evidence of endometrial cancer or any other disorder in 17 of the women with postmenopausal bleeding. The other 17 women with postmenopausal bleeding did have endometrial cancer

Impedance to uterine blood flow (as reflected by pulsatility index) in women with and without postmenopausal bleeding and endometrial cancer

\begin{tabular}{llcccc}
\hline \multirow{2}{*}{$\begin{array}{l}\text { Site of analysis of } \\
\text { blood flow }\end{array}$} & Group & No of women & Mean (SD) & Minimum & Maximum \\
\cline { 3 - 6 } Uterine arteries & $\begin{array}{c}\text { No postmenopausal } \\
\text { bleeding, no cancer } \\
\text { Postmenopausal bleeding, } \\
\text { no cancer } \\
\text { Postmenopausal bleeding, } \\
\text { cancer }\end{array}$ & 17 & $17.62(1.06)$ & 2.50 & $7 \cdot 11$ \\
Within tumour & $\begin{array}{c}\text { Postmenopausal bleeding, } \\
\text { cancer }\end{array}$ & 10 & $0.49(1.30)$ & 1.95 & 6.40 \\
\hline
\end{tabular}

and were referred for surgery. After laparotomy and histological evaluation of the excised tissue the disease was staged according to the classification of the International Federation of Gynaecology and Obstetrics; six women had stage IA disease, three stage IB, four stage IC, one stage IIA, and three stage IIIA.

The table shows the impedance to uterine arterial blood flow (mean of values for both arteries) as reflected by the pulsatility index. ${ }^{3}$ The values in the women with postmenopausal bleeding who did not have endometrial cancer and in those without postmenopausal bleeding were similar. Conversely, the highest value in the group with cancer $(1.49)$ was below the lowest value in the group without cancer $(1.95)$. The values obtained in the two groups of women with postmenopausal bleeding were logarithmically transformed to approximate normal distributions, and the overlap was estimated by using the means and standard deviations. We calculated that a cut off value of 2.00 would give a detection rate of $99 \cdot 0 \%$ with a false positive rate of $2 \cdot 6 \%$. Consequently the calculated predictive value of a positive result of screening in women with postmenopausal bleeding (assuming the prevalence of endometrial cancer to be $10 \%$ ) would be $80.9 \%$ and the predictive value of a negative result would be $99 \cdot 9 \%$. The odds ratio for the diagnosis of cancer from subsequent examination of an endometrial biopsy specimen would be reduced from 1:9 against to about 5:1 in favour.

We also determined the pulsatility index in the tumour in 10 women with endometrial cancer. The values obtained were similar to the uterine arterial index in three women and lower in seven (table).

\section{Comment}

We believe that these preliminary data show the great potential of transvaginal pulsed Doppler ultrasonography, particularly with colour flow imaging. Our findings and those of others ${ }^{4}$ suggest that indices of intratumoral blood flow will be even more sensitive markers of endometrial cancer than those of uterine arterial blood flow. In contrast, measurements of endometrial (or tumoral) thickness in the same women (taking a cut off value of $0.5 \mathrm{~cm}$ as the upper limit of normal) yielded a rate of detection of cancer of $99 \%$ but a false positive rate of $41 \%$. We are investigating other factors that may affect uterine blood flow-for example, fibroids, hyperplasia, or infection. We are also collecting data to assess whether colour flow imaging might be used to screen women without symptoms of endometrial cancer. The ultimate aim is to detect the disease at an early stage when surgery might reduce the mortality (currently about 1050 women die of the disease each year in the United Kingdom). Sequential use of the technique to detect vascularisation and locate appropriate vessels for measuring impedance to blood flow in the uterus and ovaries should permit early detection of malignant tumours in both organs at the same examination.

THB is supported by the Cancer Research Campaign and MIW by the Imperial Cancer Research Fund. We thank Aloka Ltd, Japan, and Keymed Medical and Industrial Instruments Ltd, Southend, for lending us ultrasound equipment.

Osmers R, Völksen M, Shauer A. Vaginosonography for early detection of endometrial carcinoma? Lancet 1990;335:1569-71.

2 Steer CV, Campbell S, Pampiglione JS, Kingsland CR, Mason BA, Collins WP. Transvaginal colour flow imaging of the uterine arteries during the ovarian and menstrual cycles. Hum Reprod 1990;5:391-5.

3 Bourne T, Campbell S, Steer C, Whitehead MI, Collins WP. Transvaginal colour flow imaging: a possible new screening technique for ovarian cancer. BrMed f 1989;299:1367-70.

4 Kurjak A, Zalud I, Jurkovic D, Alfirovic Z, Miljan M. Transvaginal color flow Doppler for the assessment of pelvic circulation. Acta Obstet Gynecol Scand 1989;68:131-5.

(Accepted 19 fune 1990) 